\title{
SURGICAL TREATMENT FOR RHIZARTHROSIS: A SYSTEMATIC REVIEW OF THE LAST 10 YEARS
}

\section{TRATAMENTO CIRÚRGICO DE RIZARTROSE: UMA REVISÃO SISTEMÁTICA DOS ÚLTIMOS DEZ ANOS}

\author{
Ricardo lucca Cabarite Saheb ${ }^{1}$ (D), Breno alves de Sousa Vaz ${ }^{1}$ (D), Thabata Pasquini Soeira ${ }^{1}$ (1), Filipe Jun Shimaoka ${ }^{10}$, \\ Carlos Fernando Pereira da Silva Herrero ${ }^{1}$ (i), Nilton Mazzer ${ }^{1}$ (i)
}

1. Universidade de São Paulo (USP), Faculdade de Medicina de Ribeirão, Department of Orthopedics and Anesthesiology, Ribeirão Preto, SP, Brasil.

\begin{abstract}
Introduction: Comparison of different surgical techniques to treat patients with rhizarthrosis or carpometacarpal osteoarthritis of the thumb. Materials and Methods: A systematic review was conducted using three electronic databases. Randomized, controlled trials in patients who underwent surgery for the treatment of rhizarthrosis were included. The literature review followed the PRISMA protocol. Results: A total of 15 articles involving a total population of 958 patients were selected. Seven different surgical techniques were compared. Conclusions: We conclude that no procedure is superior to another in terms of pain, physical function, overall patient assessment, range of motion, or strength. Outcome measurements should be standardized to enable better comparison between surgical techniques. Level of evidence II, Systematic Review.
\end{abstract}

Keywords: Rhizarthrosis. Thumb osteoarthritis. Trapeziometacarpal joint.

\section{RESUMO}

Introdução: Comparação de diferentes técnicas cirúrgicas em pacientes com rizartrose ou osteoartrite carpometacárpica do polegar. Materiais e Métodos: A revisão sistemática foi conduzida em três bancos de dados eletrônicos. Foram incluídos estudos clínicos randomizados e controlados com pacientes submetidos ao tratamento cirúrgico para tratamento de rizartrose. A revisão da literatura seguiu o protocolo PRISMA. Resultados: Foram selecionados 15 artigos, envolvendo uma população total de 958 pacientes. Foram comparadas sete técnicas cirúrgicas distintas. Conclusões: Concluímos que nenhum procedimento é superior a outro em termos de dor, função física, avaliação geral do paciente, amplitude de movimento ou força. A mensuração dos desfechos obtidos devem ser padronizadas a fim de possibilitar melhor comparação entre as técnicas cirúrgicas assim como, permitir uma análise estatística fidedigna. Nível de Evidência ll; Revisão Sistemática.

Descritores: Rizartrose. Osteoartrite do polegar. Articulação trapeziometacárpica.

Citation: Saheb RLC, Vaz BAS, Soeira TP, Shimaoka FJ, Herrero CFPS, Mazzer N. Surgical treatment for rhizarthrosis: a systematic review of the last 10 years. Acta Ortop Bras. [online]. 2022;30(1): Page 1 of 4 . Available from URL: http://www.scielo.br/aob.

\section{INTRODUCTION}

Rhizarthrosis or thumb carpometacarpal osteoarthritis (CMC OA) is a common condition of pain and functional limitation in the hand. CMC OA affects $66 \%$ of women older than 55 years ${ }^{1}$ and an estimated $22 \%$ of the general population aged 50 years and over are symptomatic ${ }^{2}$ Typically, patients have pain in the base of the thumb and with the progression of the disease: atrophy of thenar muscles, subluxation of the first carpometacarpal joint, loss of pinch and grip strength. Eaton et al. ${ }^{3}$ describes 4 stages of thumb joint $\mathrm{OA}$, based on radiological criteria with the end stage involving $\mathrm{CMC}$ and scaphotrapeziotrapezoid (STT) joints. In the early stages, patients can be treated with splinting of the thumb, along with anti-inflammatory drugs, steroid injections, and thumb-strengthening exercise ${ }^{4}$. Orthosis may reduce pain, however it does not improve function, dexterity and strength ${ }^{5}$.
For those who fail nonsurgical treatment, surgery must be considered. Several surgical techniques have been performed, and include: trapezial excision with or without ligament reconstruction and tendon interposition (LRTI), arthroscopy and debridement, arthroplasty, trapeziometacarpal arthrodesis (TMA) ${ }^{6}$.

In 2010, Vermeulen et $\mathrm{al}^{7}$ published a systematic review including 35 articles, 9 of which not included in previous reviews.

This study aimed to conduct a systematic review of randomized controlled studies on different kinds of surgical treatment in rhizarthrosis from the last 10 years.

\section{MATERIALS AND METHODS}

This review followed the PRISMA protocol ${ }^{8}$. The search was carried out in the PUBMED, EMBASE, and Cochrane databases using the following terms (PICOS method): Patient: rhizarthrosis (Eaton

All authors declare no potential conflict of interest related to this article.

The study was conducted at the Hospital das Clínicas de Ribeirão Preto, Universidade de São Paulo, Ribeirão Preto, SP, Brazil.

Correspondence: Ricardo Lucca Cabarite Saheb. Av. dos Bandeirantes 3900, 11º andar, Ribeirão Preto, SP, Brazil. 14048-900. rsaheb@usp.br 
stages II-IV) ; Intervention: Surgery; Comparison: Different kinds of surgical treatment; Outcomes: Pain, function, grip and pinch strength; Study design: randomised controlled trials.

The review was conducted in October 2019 and repeated in April 2020, and included studies from the last ten years (between 2011 to 2019) (Figure 1). Search terms included "rhizarthrosis", "thumb carpometacarpal joint" and "thumb osteoarthritis". There was no restriction on publication language. First of all, a list was created with the titles and abstracts of studies potentially relevant and two independent reviewers (R.L.C.S and B.A.S.V.) applied the search. If the abstract suggested inclusion in our study, the full manuscript was retrieved and reviewed. Conflicts could be solved by a third researcher, however it was not necessary.

The same two reviewers, in an independent manner, extracted the data, which included: participants, intervention, comparison between techniques, scores, results and conclusion.

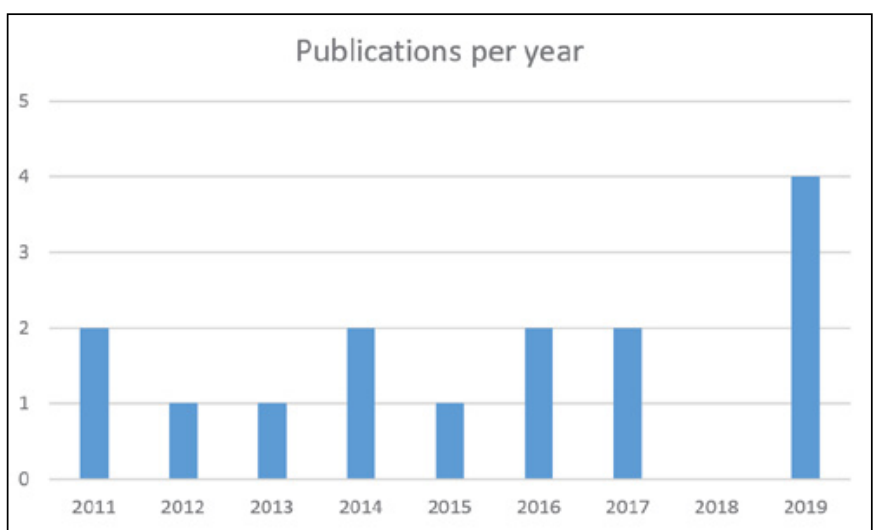

Figure 1. Publications per year.

\section{RESULTS}

A total of 29 articles contained titles and abstracts relevant to the study and were selected for a complete reading of the text. After this stage, 15 articles were included, of which 958 patients were selected. Five studies compared different techniques of trapezial excision with ligament reconstruction and tendon interposition (LRTI). Esenwein et al. $(2011)^{9}$, compared T + LRTI using abductor pollicis longus (APL) or flexor carpi radialis (FCR). Similar results can be obtained using the technically less demanding APL-procedure when compared with the FCR-technique 8 months postoperatively. Vermeulen et al. $(2014)^{10}$, compared T + LRTI (FCR) with or without bone tunnel, and obtained faster recovery in tunnel group, however, 12 months after surgery, the functional outcome was similar. Spekreijse et al. ${ }^{11}$ (2015), comparing T + LRTI(FCR) with or without bone tunnel, showed that improved function, strength, and satisfaction obtained at 1 year after, was maintained after 5 years. Zajonc et al. ${ }^{12}$ (2016), in 38 patients, compared T + LRTI (APL) from Lundborg and Sirotakova techniques. Both resection-suspension arthroplasty procedures led to a statistically significant postoperative reduction of pain, a significant improvement in radial and palmar abduction, a significant gain in quality of life and significant asymptomatic proximalization of the first metacarpal bone. Nanno et al.13 (2019), compared T + LRTI (APL) original and modified. There were no statistically significant differences in the thumb palmar abduction angle, pinch power, grip strength, Quick DASH score, or VAS score between groups. Patients in group 2 had a significantly better range of motion of radial abduction.

Three studies compared trapeziectomy versus trapeziectomy with or without LRTI. Salem et al. ${ }^{14}$ (2011) and Gangopadhyay et al..$^{15}$ (2012), studying 114 and 153 patients, respectively showed similar objective and subjective outcomes between groups, so there appears to be no benefit to tendon interposition or ligament reconstruction in the longer term, furthermore Corain et al. ${ }^{16}$ (2016), demonstrated that the trapezium excision and bone space distraction technique requires a smaller incision, a shorter surgical time, an easier surgical technique, and a less painful recovery, maintaining overlapping levels of functional restore.

Other three studies compared trapezial excision with or without LRTI versus trapeziometacarpal arthrodesis (TMA). The first study by Vermeulen et al. ${ }^{17}$ was published in 2014. This study in 38 patients showed similar results in DASH and PRWHE scores twelve months after surgery, however fewer moderate and severe complications were related after trapeziectomy with ligament reconstruction and tendon interposition. A second study was published by Hippensteel et al. ${ }^{18}$ in 2017, comparing 52 patients. There were no significant differences in the amount of change in grip or pinch strength, patientreported outcomes, or functional hand testing between groups. The incidence of complications was similar between operative groups, but revision surgery was more common after TMA. The third study from Li et al. ${ }^{19}$ published in 2019, in 39 patients, showed that arthrodesis displayed better pinch strength, while arthroplasty displayed better motor function. Patients were satisfied with the effects of both techniques.

One study compared arthroplasty versus trapeziectomy and LRTI (Thorkildsen et al. 2019) ${ }^{20}$, in 40 patients. The results in the early rehabilitation were significantly better in the joint replacement group, as well as the range of motion in abduction and extension was better at the final follow-up. Patient satisfaction was high in both groups despite more complications after joint replacement. Trapeziectomy with ligament reconstruction and tendon interposition proved to be a safe and effective treatment with few complications in this trial. Another study compared arthroplasty cemented and uncemented (Hansen et al. 2013) ${ }^{21}$, with 16 patients in each group, showing similar good results between groups at all measurement points in grip strength, pain and DASH score.

Another one study compared trapezial excision versus trapezial denervation. Salibi et al. ${ }^{22}$ (2019), in 45 patients, associated trapezial denervation with fast recovery, by the other hand $30 \%$ of these patients needed a reoperation.

The last study compared trapezial excision with LRTI versus trapezial excision and allograft. This study from Marks et al. ${ }^{23}$, published in 2017, comparing 60 patients, showed similar outcomes, with more complications in the second group. Allograft was used only in cases of severe instability.

The DASH (The Disabilities of the Arm, Shoulder and Hand) score was the most frequently used ( 9 articles), followed by VAS (Visual Analogue Scale) (8 articles). (Figure 2).

The rhizarthrosis stage was classified according to Eaton in 12 articles. Three studies did not define the classification.

\section{DISCUSSION}

The aim of the study was to provide an updated review of the current literature (last 10 years), according to most used surgical procedures. We did not perform a statistical analysis because of the great heterogeneity between the included articles. Our search strategy identified 15 articles, none of them includes in previous systematic reviews.

First, we reviewed five studies comparing different techniques of trapeziectomy with ligament reconstruction and tendon interposition. No evidence of superiority between techniques was demonstrated. The second group of studies, compared trapeziectomy alone and trapeziectomy with or without LRTI. Similar objective and subjective outcomes were obtained between groups, moreover trapezium 
excision isolated requires a smaller incision, a shorter surgical time, an easier and a less painful recovery.

The third group, including three studies, compared trapezial excision with or without LRTI versus trapeziometacarpal arthrodesis (TMA). Complications and repeat surgeries are more frequent following TMA compared to trapeziectomy with or without LRTI. One author suggested that arthrodesis displayed better pinch strength, while arthroplasty displayed better motor function.

When evaluating the study on arthroplasty versus trapezial excision with LRTI, we conclude that the results in the early rehabilitation were significantly better in the joint replacement group, as well as the range of motion in the final follow-up, by the other hand more complications were associated to the joint replacement group.

The study comparing cemented and uncemented arthroplasty, showed similar good results with both techniques.

Another study compared trapezial excision versus trapezial denervation and concluded that $30 \%$ of patients undergone trapezial denervation, needed a second surgical procedure.

Finally, an article comparing trapezial excision with LRTI versus trapezial excision and allograft, conclude that allograft should be used only in cases of severe instability, due to associated complications with the technique (Tables 1 and 2).

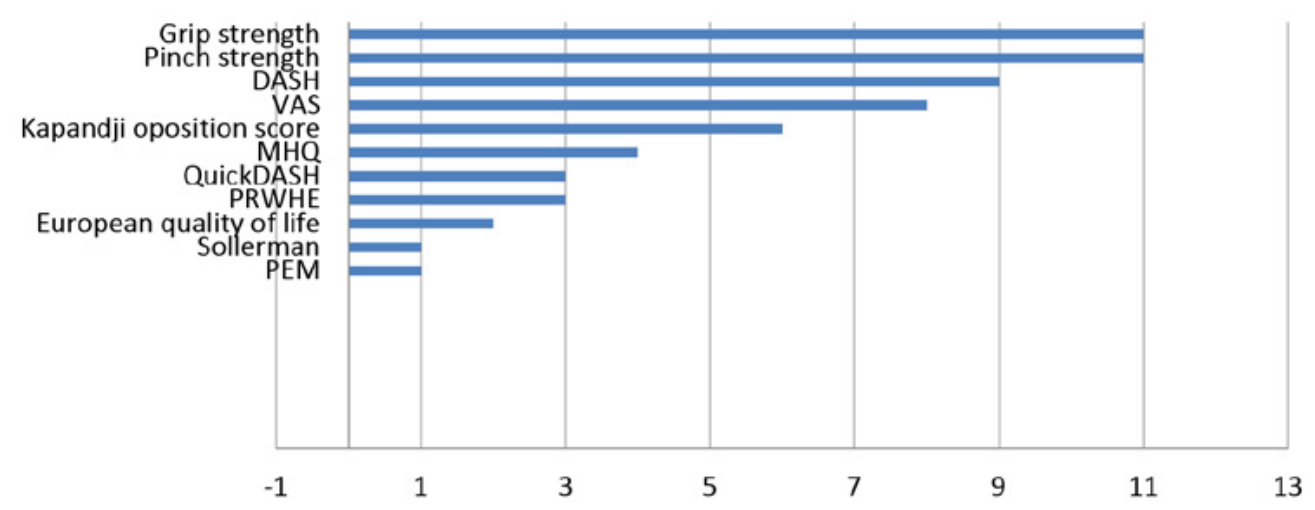

Figure 2. The Disabilities of the Arm, Shoulder and Hand; VAS = Visual Analogue Scale; MHQ = Michigan Hand Outcome Questionnaire; PRWHE = Patient rate wrist/hand.

Table 1. Studies conclusions.

\begin{tabular}{|c|c|c|c|c|}
\hline Authors & Study & $\begin{array}{l}\text { № of patients } \\
\text { per group }\end{array}$ & Procedure & Author's conclusion \\
\hline \multirow[b]{2}{*}{$\begin{array}{l}\text { Hippensteel } \\
\text { et al. }{ }^{6}(2017)\end{array}$} & \multirow[b]{2}{*}{$\mathrm{RCT}$} & 27 & CMC arthrodesis & \multirow{2}{*}{$\begin{array}{l}\text { There were no significant differences in the amount of change in grip or pinch strength, } \\
\text { patient-reported outcomes, or functional hand testing between TMA and LRTI. The } \\
\text { TMA group had significantly increased thumb tip opposition distance. The TMA group } \\
\text { was complicated by a } 26 \% \text { overall nonunion rate of which } 8 \% \text { were symptomatic. The } \\
\text { LRTI group (Wagner incision) had a significantly increased incidence of superficial } \\
\text { branch of the radial nerve paresthesia. The incidence of complications was similar } \\
\text { between operative groups, but revision surgery was more common after TMA. }\end{array}$} \\
\hline & & 25 & LRTI & \\
\hline \multirow{2}{*}{$\begin{array}{l}\text { Esenwein et } \\
\text { al. }{ }^{9}(2011)\end{array}$} & \multirow{2}{*}{$\mathrm{RCT}$} & 30 & $\mathrm{~T}+\mathrm{LRTI}(\mathrm{APL})$ & \multirow{2}{*}{$\begin{array}{l}\text { Similar results can be obtained using the technically less demanding APL-procedure } \\
\text { when compared with the FCR-technique } 8 \text { months postoperatively. }\end{array}$} \\
\hline & & 25 & T+LRTI (FCR) & \\
\hline \multirow{2}{*}{$\begin{array}{l}\text { Vermeulen et } \\
\text { al. } .^{10}(2014)\end{array}$} & \multirow[b]{2}{*}{$\mathrm{RCT}$} & 36 & T+ LRTI(FCR) with tunnel & \multirow{2}{*}{$\begin{array}{l}\text { After the bone tunnel technique, patients have better function and less pain } 3 \text { months } \\
\text { after surgery than do those in the nonebone tunnel group, which indicates faster } \\
\text { recovery. However, } 12 \text { months after surgery, the functional outcome was similar. }\end{array}$} \\
\hline & & 36 & $\mathrm{~T}+\mathrm{LRTI}(\mathrm{FCR})$ without tunnel & \\
\hline \multirow{2}{*}{$\begin{array}{l}\text { Spekreijse et } \\
\text { al. }{ }^{11}(2015)\end{array}$} & \multirow[b]{2}{*}{$\mathrm{RCT}$} & 36 & $\mathrm{~T}+\mathrm{LRTI}(\mathrm{FCR})$ with tunnel & \multirow{2}{*}{$\begin{array}{l}\text { This study showed that improved function, strength, and satisfaction obtained } \\
\text { at } 1 \text { year after trapeziectomy with LRTI with or without the use of a bone tunnel } \\
\text { for stage IV TMC thumb osteoarthritis was maintained after } 5 \text { years. }\end{array}$} \\
\hline & & 36 & $\mathrm{~T}+\mathrm{LRTI}(\mathrm{FCR})$ without tunnel & \\
\hline \multirow[b]{2}{*}{$\begin{array}{l}\text { Zajonc et al. } \\
{ }_{12}(2016)\end{array}$} & \multirow[b]{2}{*}{$\mathrm{RCT}$} & 19 & T + LRTI(APL) Lundborg & \multirow{2}{*}{$\begin{array}{l}\text { Both resection-suspension arthroplasty procedures led to a statiscally signifcant } \\
\text { postoperative reducion of pain, a significant improvement in radial and palmar abduction } \\
\text { a significant gain in quality of life and signifcant assymptomatic proximalisation of the } \\
\text { first metacarpal bone. There was no signifcant difference in postoperative strength. }\end{array}$} \\
\hline & & 19 & T + LRTI(APL) Sirotakova & \\
\hline \multirow{2}{*}{$\begin{array}{l}\text { Nanno et } \\
\text { al. }^{13}(2019)\end{array}$} & \multirow[b]{2}{*}{$\mathrm{RCT}$} & 10 & $\mathrm{~T}+\mathrm{LRTI}$ (APL original) & \multirow{2}{*}{$\begin{array}{l}\text { There were no statiscally significant differences in the thumb palmar abduction } \\
\text { angle, pinch power, grip strength, Quick DASH score, or VAS score between groups. } \\
\text { Patients in group } 2 \text { had a significantly better range of motion of radial abduction. }\end{array}$} \\
\hline & & 20 & T+LRTI(APL modif) & \\
\hline \multirow[b]{2}{*}{$\begin{array}{l}\text { Salem et } \\
\text { al. }^{14}(2011)\end{array}$} & \multirow[b]{2}{*}{$\mathrm{RCT}$} & 59 & $T$ & \multirow{2}{*}{$\begin{array}{l}\text { There were no significant differences between the two treatments in any } \\
\text { subjective or objective outcome measure at 6-year follow-up Eighty-two percent } \\
\text { of the thumbs were painless or only ached after use. The DASH and Patient } \\
\text { Evaluation Measure scores were significantly better than preoperatively. }\end{array}$} \\
\hline & & 55 & T+LRTI (FCR) & \\
\hline \multirow{3}{*}{$\begin{array}{l}\text { Gangopadhyay } \\
\text { et al. }{ }^{15}(2012)\end{array}$} & \multirow{3}{*}{$\mathrm{RCT}$} & 53 & $\mathrm{~T}$ & \multirow{3}{*}{$\begin{array}{l}\text { The outcomes of these } 3 \text { variations of trapeziectomy were similar after a } \\
\text { minimum follow-up of } 5 \text { years. There appears to be no benefit to tendon } \\
\text { interposition or ligament reconstruction in the longer term }\end{array}$} \\
\hline & & 46 & $\mathrm{~T}+\mathrm{Tl}(\mathrm{PL})$ & \\
\hline & & 54 & T +LRTI (FCR) & \\
\hline
\end{tabular}




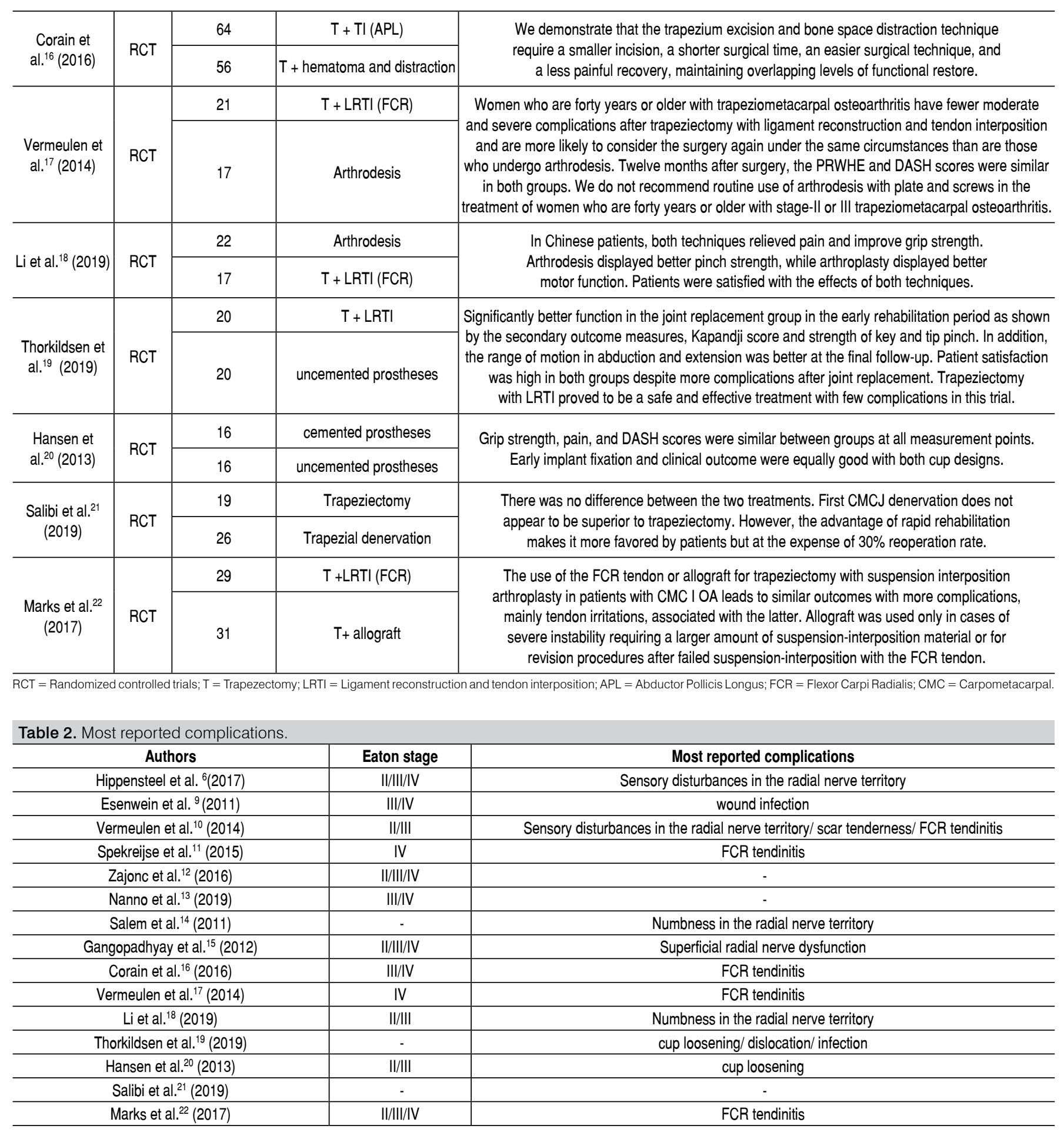

\section{CONCLUSION}

We conclude that no procedure is superior to another in terms of pain, physical function, patient global assessment, range of motion, or strength. Furthermore, because differences between the various techniques are small, researchers should focus on developing more sensitive outcome measures that are indicative of the specific changes in hand function after CMC OA. We suggest that outcomes measures be standardized. The Disabilities of the Arm, Shoulder and Hand (DASH) perhaps the most indicated like a Patient Report Outcomes (PRO), in association with Visual Analogue Scale (VAS), grip and pinch strengths.

AUTHORS' CONTRIBUTION: Each author contributed individually and significantly to the development of the manuscript. RLCS : writing and review of the article; BASV: data analysis and article writing; TS : statistical analysis, and article review; FJS: data analysis and review of the article; $\mathrm{CH}$ : writing and review of the article and also in the entire intellectual concept of the article; NM : writing of the article, statistical analysis and intellectual concept of the article and preparation of the entire research project 


\section{REFERENCES}

1. Haara MM, Heliövaara M, Kröger $H$, Arokoski JPA, Manninen P, Kärkkäinen $A$, et al. Osteoarthritis in the carpometacarpal joint of the thumb: Prevalence and associations with disability and mortality. J Bone Joint Surg Am. 2004;86(7):1452-7.

2. Marshall M, van der Windt D, Nicholls E, Myers $H$, Dziedzic K. Radiographic thumb osteoarthritis: frequency, patterns and associations with pain and clinical assessment findings in a community-dwelling population. Rheumatology (Oxford). 2011;50(4):735-9.

3. Eaton RG, Glickel SZ. Trapeziometacarpal osteoarthritis. Staging as a rationale for treatment. Hand Clin. 1987;3(4):455-71.

4. Swigart CR, Eaton RG, Glickel SZ, Johnson C. Splinting in the treatment of arthritis of the first carpometacarpal joint. J Hand Surg Am. 1999;24(1):86-91.

5. Spaans AJ, van Minnen LP, Kon M, Schuurman AH, Schreuders ART, Vermeulen GM. Conservative treatment of thumb base osteoarthritis: a systematic review. J Hand Surg Am. 2015;40(1):16-21.e1-6.

6. Hippensteel KJ, Calfee R, Dardas AZ, Gelberman R, Osei D, Wall L. Functional outcomes of thumb trapeziometacarpal arthrodesis with a locked plate versus ligament reconstruction and tendon interposition. J Hand Surg Am. 2017;42(9):685-92.

7. Vermeulen GM, Slijper H, Feitz R, Hovius SER, Moojen TM, Selles RW. Surgical management of primary thumb carpometacarpal osteoarthritis: a systematic review. J Hand Surg Am. 2011;36(1):157-69.

8. Moher D, Liberati A, Tetzlaff J, Altman DG, PRISMA Group. Preferred reporting items for systematic reviews and meta-analyses: the PRISMA statement. Int J Surg. 2010;8(5):336-41.

9. Esenwein $P$, Hoigne D, Zdravkovic V, Sanchez T. Resection, interposition and suspension arthroplasty for treatment of Basal joint arthritis of the thumb: a randomized and prospective comparison of techniques using the abductor pollicis longus- and the flexor carpi radialis tendon. Handchir Mikrochir Plast Chir. 2011;43(5):289-94.

10. Vermeulen GM, Spekreijse KR, Slijper H, Feitz R, Hovius SER, Selles RW. Comparison of arthroplasties with or without bone tunnel creation for thumb basal joint arthritis: a randomized controlled trial. J Hand Surg Am. 2014;39(9):1692-8.

11. Spekreijse KR, Vermeulen GM, Kedilioglu MA, Slijper HP, Feitz R, Hovius SE, et al. The effect of a bone tunnel during ligament reconstruction for trapeziometacarpal osteoarthritis: A 5-year follow-up. J Hand Surg Am. 2015;40(11):2214-22.
12. Zajonc H, Grill B, Simunovic F, Lampert F, Stark GB, Penna V. Comparison of the results of Lundborg's and Sirotakova's resection-suspension arthroplasty for the treatment of trapeziometacarpal joint osteoarthritis. Handchir Mikrochir Plast Chir. 2016;48(3):161-7.

13. Nanno M, Kodera N, Tomori Y, Takai S. Novel modification of abductor pollicis longus suspension arthroplasty with trapeziectomy for thumb carpometacarpa osteoarthritis. J Nippon Med Sch. 2019;86(5):269-78.

14. Salem H, Davis TRC. Six year outcome excision of the trapezium for trapeziometacarpal joint osteoarthritis: is it improved by ligament reconstruction and temporary Kirschner wire insertion? J Hand Surg Eur Vol. 2012;37(3):211-9.

15. Gangopadhyay S, McKenna H, Burke FD, Davis TRC. Five- to 18-year follow-up for treatment of trapeziometacarpal osteoarthritis: a prospective comparison of excision, tendon interposition, and ligament reconstruction and tendon interposition. J Hand Surg Am. 2012;37(3):411-7.

16. Corain M, Zampieri N, Mugnai R, Adani R. Interposition arthroplasty versus hematoma and distraction for the treatment of osteoarthritis of the trapeziometacarpal joint. J Hand Surg Asian Pac. 2016;21(1):85-91.

17. Vermeulen GM, Brink SM, Slijper H, Feitz R, Moojen TM, Hovius SER, et al. Trapeziometacarpal arthrodesis or trapeziectomy with ligament reconstruction in primary trapeziometacarpal osteoarthritis: a randomized controlled trial: A randomized controlled trial. J Bone Joint Surg Am. 2014;96(9):726-33.

18. Li J, Li D, Tian G, Zhang W. Comparison of arthrodesis and arthroplasty of Chinese thumb carpometacarpal osteoarthritis. J Orthop Surg Res. 2019;14(1):404.

19. Thorkildsen RD, Røkkum M. Trapeziectomy with LRTI or joint replacement for CMC1 arthritis, a randomised controlled trial. J Plast Surg Hand Surg. 2019;53(6):361-9.

20. Hansen TB, Stilling M. Equally good fixation of cemented and uncemented cups in total trapeziometacarpal joint prostheses. A randomized clinical RSA study with 2-year follow-up: A randomized clinical RSA study with 2-year follow-up. Acta Orthop. 2013;84(1):98-105.

21. Salibi A, Hilliam R, Burke FD, Heras-Palou C. Prospective clinical trial comparing trapezial denervation with trapeziectomy for the surgical treatment of arthritis at the base of the thumb. J Surg Res. 2019;238:144-51.

22. Marks M, Hensler S, Wehrli M, Scheibler A-G, Schindele S, Herren DB. Trapeziectomy with suspension-interposition arthroplasty for thumb carpometacarpal osteoarthritis: A randomized controlled trial comparing the use of allograft versus flexor carpi radialis tendon. J Hand Surg Am. 2017;42(12):978-86. 